Research Paper

\title{
A predictive model for confined and unconfined nucleate boiling heat transfer coefficient
}

\author{
Igor Seicho Kiyomura ${ }^{a}$, Taye Stephen Mogaji ${ }^{a, b}$, Leonardo Lachi Manetti ${ }^{a}$, Elaine Maria Cardoso ${ }^{\mathrm{a}, *}$

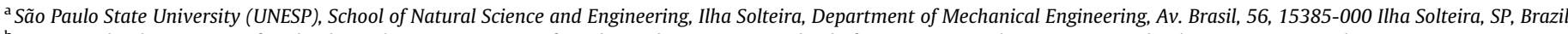 \\ ${ }^{\mathrm{b}}$ FUTA - Federal University of Technology Akure, Department of Mechanical Engineering, School of Engineering and Engineering Technology, PMB 704, Ondo State, Nigeria
}

\section{H I G H L I G H T S}

- An analysis of the influences of different parameters on the boiling phenomenon was performed.

- A new correlation to predict the pool boiling heat transfer coefficient is presented.

- The effect of different working fluids, gap size and surface roughness were considered.

- The proposed correlation predicts accurately the boiling heat transfer of fluids under confined and unconfined conditions.

\section{A R T I C L E I N F O}

\section{Article history:}

Received 27 May 2017

Revised 19 August 2017

Accepted 28 August 2017

Available online 31 August 2017

\section{Keywords:}

Heat transfer coefficient

Correlation

Confined and unconfined boiling

Contact angle

\begin{abstract}
A B S T R A C T
The aim of this study is to investigate the influences of different parameters on the boiling phenomenon. In this paper, a new correlation to predict the pool boiling heat transfer coefficient is presented. The developed correlation was based on a database of experimental results, taking into account the effect of surface/liquid combination by considering the influence of contact the angle on pool boiling performance, and also the effect of the nucleate boiling in narrow spaces. The proposed correlation predicts accurately the boiling heat transfer behavior of fluids with significantly different thermophysical properties under confined and unconfined conditions. In order to validate the developed correlation, statistical analyses on the ratios of the experimental and correlated Nusselt numbers were performed. Also, the heat transfer coefficients calculated with the proposed correlation were compared with experimental results for different pool boiling conditions obtained by others authors.
\end{abstract}

(c) 2017 Elsevier Ltd. All rights reserved.

\section{Introduction}

A better understanding of the mechanisms governing the nucleate boiling is required in order to intensify its use in thermal systems. Although intensive research on pool boiling processes has been undertaken for decades, the physical phenomena are still not sufficiently understood. This is mainly due to the large number of influencing parameters on the boiling process. The main factors that influence the heat transfer mechanisms in nucleate boiling regime are the heat flux, the thermophysical properties of the working fluid and the surface characteristics such as the dimensions, geometric shape, thickness, orientation, and roughness [1]. The investigations on this subject have three major objectives: (i) reducing the heat exchanger size; (ii) operate at heat flux safety margins, and (iii) increasing the heat transfer rate.

\footnotetext{
* Corresponding author.

E-mail address: elainemaria@dem.feis.unesp.br (E.M. Cardoso).
}

The mainly parameters of boiling heat transfer according to $\mathrm{Li}$ et al. [2] are the heat transfer coefficient (HTC) and the critical heat flux (CHF). The former determines the cooling system's efficiency, and the latter determines the cooling system's maximum dissipation power and safety constraints. Moreover, the CHF can be highly dependent on the confinement, and the general trend is that it decreases with a decrease of the gap size [3]. Kole and Dey [4] established that boiling phenomena of fluids are important for systems which are characterized by high heat flux in a compact volume. Thus, in order to apply the boiling process in the engineering field toward producing more compact and efficient thermal systems, a full understanding of the boiling phenomenon is required.

The application of nucleate boiling in confined spaces is one of the techniques used to improve thermal exchange. The first studies focusing on confined boiling were performed by Ishibashi and Nishikawa [5] and Katto et al. [6]. In the former, the authors presented an analysis of the effect of pressure, surface tension and 


\begin{tabular}{|c|c|c|c|}
\hline \multicolumn{4}{|c|}{ Nomenclature } \\
\hline \multicolumn{2}{|c|}{ Alphabetic } & \multicolumn{2}{|c|}{ Greek letters } \\
\hline$c_{p}$ & specific heat capacity [J/kg K] & $\Delta T_{\text {sat }}$ & wall superheating [K] \\
\hline$C_{s}$ & surface-fluid parameter [-] & $\gamma$ & heating surface material parameter $[-]$ \\
\hline$f_{w}$ & surface material parameter [-] & $\gamma_{30}$ & parcel of data correctly predicted within $\pm 30 \%$ range $[-]$ \\
\hline$g$ & acceleration due to gravity $\left[\mathrm{m} / \mathrm{s}^{2}\right]$ & $\mu$ & viscosity $[\mathrm{kg} / \mathrm{m} \mathrm{s}]$ \\
\hline$k$ & thermal conductivity $[\mathrm{W} / \mathrm{m} \mathrm{K}]$ & $\theta$ & static contact angle $\left[{ }^{\circ}\right]$ \\
\hline$L_{b}$ & capillary length $[\mathrm{m}]$ & & \\
\hline$M$ & molar mass $[\mathrm{kg} / \mathrm{kmol}]$ & \multicolumn{2}{|c|}{ Subscripts } \\
\hline$p_{a t m}$ & atmospheric pressure $[\mathrm{kPa}]$ & $l$ & liquid \\
\hline$p_{r}$ & reduced pressure $[\mathrm{kPa}]$ & $v$ & vapor \\
\hline q" & heat flux $\left[\mathrm{W} / \mathrm{m}^{2}\right]$ & & \\
\hline$T_{w}$ & surface temperature $[\mathrm{K}]$ & $\operatorname{Re}_{b}{ }^{*}$ & modified Reynolds number of the vapor bubble [-] \\
\hline$U_{b}$ & vapor bubble superficial velocity $[\mathrm{m} / \mathrm{s}]$ & $\begin{array}{l}\kappa e_{b} \\
J a^{*}\end{array}$ & modified Jakob number [-] \\
\hline$d_{b, S A}$ & $\begin{array}{l}\text { detachment diameter of vapor bubbles used in Stephan } \\
\text { and Abdelsalam's correlation [m] }\end{array}$ & $\operatorname{Pr}$ & Prandtl number $[-]$ \\
\hline$D_{b}$ & detachment diameter of vapor bubbles [m] & & \\
\hline
\end{tabular}

confinement on pool boiling in an annular vertical channel. The authors showed that the confinement leads to an increase in the heat transfer coefficients at low heat fluxes. Katto et al. [6] showed that for low to moderated heat fluxes, the confinement has a surprisingly beneficial effect, enhancing heat transfer. The enhancement of heat transfer in confined boiling is generally attributed to two different mechanisms: enhanced liquid agitation [5] and enhanced microlayer evaporation [6,7]. The former is due to the coalescence phenomenon and displacement of the bubbles along the surface and it is generally reported for vertical heating surfaces. The latter is due to the fast bubble growth forming a microlayer with a large surface; this mechanism is generally cited in studies carried out on horizontal surfaces and in very narrow spaces, when the vapor bubbles have a long residence time in the confined space.

In order to better understand the mechanisms responsible for boiling heat transfer in narrow spaces, Cardoso et al. [8] performed an experimental nucleate boiling study on a horizontal upward facing heater and on a downward facing heater, by using FC 72 and FC 87 as working fluids and for different gap sizes. The results, according to this study revealed that, for the unconfined case and at low heat fluxes, the heat transfer is higher for a downward facing heating surface than for an upward facing heating surface. However, the effect of the heater's orientation tends to disappear for the confined case.

The study of Yin et al. [9], involving experimental investigation on bubble confinement and elongation in microchannel during flow boiling of water, revealed a dominant heat transfer for confined bubble growth rate compared to free/unconfined growth bubble. According to the researchers, the heat transfer enhancement was due to the evaporation of thin liquid film surrounding the elongated bubble.

The effect of the gap size on the vapor bubble can be characterized by Bond number, Bo, defined as the ratio of the characteristic length to the confined space, $s$, and the capillary length, $L=\sqrt{\frac{\sigma}{g\left(\rho_{l}-\rho_{v}\right)}}$, where $\sigma, g, \rho_{l}$ e $\rho_{v}$ represent the surface tension $[\mathrm{N} / \mathrm{m}]$, the acceleration due to gravity $\left[\mathrm{m} / \mathrm{s}^{2}\right]$, the liquid density and the vapor density $\left[\mathrm{kg} / \mathrm{m}^{3}\right]$, respectively [10]. Guglielmini et al. [11] analysed the combined effects of surface orientation and gap size on the boiling heat transfer and CHF of HFE 7100 on a smooth copper surface. At low wall superheat, for $B o>1$, the effect of confinement was negligible for all surface orientations, while for $B o \approx 1$ and angles of $0^{\circ}$ (upward facing surface) and $45^{\circ}$, heat transfer was enhanced. At large wall superheating and with gaps of 3.5, 2 and $1 \mathrm{~mm}$, the HTC and CHF decreased as the channel width decreased.

Cardoso and Passos [1] studied saturated nucleate boiling of nPentane on an upward face heating surface for different gap sizes $(s=0.1,0.2,0.5,0.7$ and $13 \mathrm{~mm}$ ), with two different diameters of heated discs. The authors observed that for the confined case, the HTC is higher when the diameter of the heating surface is smaller. This was explained by the fact that the smaller the heated surface diameter, the lower is the residence time of vapor bubbles inside the channel. For the unconfined case, the HTC increases as the diameter of the heated surface decreases, due to the fact that decreasing the heating surface area decreases the resistance of the liquid located near the heating surface to cool it.

The effect of the heating surface condition on nucleate boiling has also called the attention of the scientific community $[12,13]$. Experimental studies have been performed using nanostructured surfaces, aiming to understand the surface modification effects. Surfaces with microporous coatings of thicknesses 81, 109, 150, 182 , and $225 \mu \mathrm{m}$ were tested in confined and unconfined spaces by Yang and Liu [14]. From the experimental results, the authors concluded that the HTC for the surfaces with microporous coatings are affected by the number of active nucleation sites, bubble detachment resistance, and the thermal resistance of the microporous coating layer.

Souza et al. [15] studied the effect of the deposition of maghemite $\left(\gamma-\mathrm{Fe}_{2} \mathrm{O}_{3}\right)$ nanoparticles on a horizontal heated copper surface during the nucleate boiling of HFE 7100, using two nanoparticle diameters $(10 \mathrm{~nm}$ and $80 \mathrm{~nm}$ ). Two main conditions are considered: unconfined and confined boiling. The results showed around $55 \%$ enhancement in the HTC of for the nanostructured surface with the smallest nanoparticles, as compared to those of the surface without deposition. The results for the larger nanoparticles showed around $29 \%$ decrease in the HTC as compared to the case 
without deposition. For the confined cases, the boiling heat transfer increased when the gap size decreased, mainly for lower heat fluxes.

Heitich et al. [16] analysed the effect of nanostructured surfaces on pool boiling of water under saturated conditions. In their experiment, molybdenum (achieved by sputtering process) and maghemite (obtained by nanofluid evaporation) were used to nanocoat the heating surface. The rough surfaces showed a highly hydrophobic behavior, and the HTC enhancement compared to the others surfaces tested was explained by the fact the cavities are not flooded with liquid, allowing vapor trapping which in turn increases the number of active boiling centers on the surface.

Recently, in order to observe the effect of nanocoating process on the HTC behavior during pool boiling process, Kiyomura et al. [17] carried out pool boiling experiments using copper surfaces with different roughnesses and DI-water as the working fluid under saturated conditions. The nanostructured surfaces were produced by boiling process of $\mathrm{Fe}_{2} \mathrm{O}_{3}$-water based nanofluid, with different nanofluid concentrations. According to the authors, the highest HTC were obtained for the nanocoated smooth surface (at low nanofluid concentration).

In order to understand the boiling phenomenon, numerous pool boiling experiments - including models and correlations - have been reported in the open literature. It is important to point out that, the accuracy of the database related to the parameters has a decisive effect on the success of the model in correlating the experimental data. Therefore, many of the models and correlations found in the literature are useful within the range of the database used in developing their derivation.

This paper initially describes the correlations available in the open literature for prediction of pool boiling heat transfer. Subsequently, the database obtained by Cardoso and Passos [1], Cardoso et al. [8] and Kiyomura et al. [17] for the heat transfer coefficient during pool boiling of FC72, FC87, n-Pentane and DI-water under confined and unconfined conditions are described and compared with the predictive methods from the literature. Then, a new correlation for confined and unconfined nucleate boiling regime, taking into account the heating surface characteristics, the working fluid properties and the interaction between them, is proposed based on the HTC experimental database of these authors. The experimental trends from the database considered for its development and independent data from literature were well captured by the proposed correlation.

\section{Predictive methods available in the literature for pool boiling heat transfer}

In the present analysis, different correlations are considered for comparison with the proposed correlation as, Gupta and Varshney as referred by Hameed et al. [18], Rohsenow [19], Stephan and Abdelsalam [20], Cooper [21], Ribatski and Jabardo [22], and Li et al. [23].

Gupta and Varshney as referred by Hameed et al. [18] developed a pool boiling heat transfer correlation based on their experimental data for distilled water, benzene, and toluene as working fluids over a heated horizontal cylinder. The correlation is given as follows:

$\frac{\mathrm{h}_{\mathrm{GV}}}{\mathrm{k}_{\mathrm{l}}} \sqrt{\frac{\sigma}{\left(\rho_{\mathrm{l}}-\rho_{\mathrm{v}}\right) \mathrm{g}}}=1.39\left(\frac{\mathrm{q}^{\prime \prime} \rho_{\mathrm{l}} \mathrm{c}_{\mathrm{pl}}}{\rho_{\mathrm{v}} \mathrm{h}_{\mathrm{lv}} \mathrm{k}_{\mathrm{l}}} \sqrt{\frac{\sigma}{\left(\rho_{\mathrm{l}}-\rho_{\mathrm{v}}\right) \mathrm{g}}}\right)^{0.7}\left(\frac{\rho_{\mathrm{v}}}{\rho_{\mathrm{l}}}\right)^{0.21}\left(\frac{\mu_{\mathrm{l}} \mathrm{c}_{\mathrm{pl}}}{\mathrm{k}_{\mathrm{l}}}\right)^{-0.21}$

Rohsenow [19] assumes that the movement of bubbles at the time of departure from the heating surface is the predominant mechanism and used different constants to express the effects of various materials, conditions and types of surface. For heat transfer in the region of nucleation pool boiling, the heat transfer is given as follows:

$\frac{c_{p l} \Delta T_{s a t}}{h_{l v}}=C_{s f}\left[\frac{q^{\prime \prime}}{\mu_{l} h_{l v}} \sqrt{\frac{\sigma}{g\left(\rho_{l}-\rho_{v}\right.}}\right]^{r} \operatorname{Pr}_{l}^{s}$

where $\mu_{l}, h_{l v}, c_{p l}$, and $\operatorname{Pr}_{l}$ represent the viscosity of the liquid $(\mathrm{kg} /$ $\mathrm{m} \mathrm{s})$, the latent heat of vaporization $(\mathrm{J} / \mathrm{kg})$, the specific heat of the liquid $(\mathrm{J} / \mathrm{kg} \mathrm{K})$, and the Prandtl number of the liquid, respectively. $\Delta T_{\text {sat }}$ represents the wall superheating, i.e., $\left(T_{w}-T_{\text {sat }}\right)$, and $r=1 / 3$ and $s=1.7$ (for water, $s$ is equal to 1.0). Rohsenow [19] proposed the surface factor $C_{s f}$ as variable coefficient depending on the combination of the heating wall material and roughness, as well as, the working fluid.

In 1980, Stephan and Abdelsalam [20] proposed four specific correlations by applying a statistical multiple regression technique to water, refrigerants, organics, and cryogens. They proposed the following correlation for refrigerants, whose mean deviation was $10.6 \%$ in the reduced pressure range of $0.003-0.78$,

$\mathrm{h}_{\mathrm{SA}}=207\left(\frac{\mathrm{k}_{\mathrm{l}}}{\mathrm{d}_{\mathrm{b}, \mathrm{SA}}}\right)\left(\frac{\mathrm{q}^{\prime \prime} \mathrm{d}_{\mathrm{b}, \mathrm{SA}}}{\mathrm{k}_{\mathrm{l}} \mathrm{T}_{\mathrm{sat}}}\right)^{0.745}\left(\frac{\rho_{\mathrm{v}}}{\rho_{\mathrm{l}}}\right)^{0.581} \operatorname{Pr}_{1}^{0.533} \mathrm{R}_{\mathrm{p}}^{0.333}$

where $k_{l}$ represents the thermal conductivity of the liquid, and $d_{b, S A}$ the detachment diameter of the bubble, calculated by:

$\mathrm{d}_{\mathrm{b}, \mathrm{SA}}=0.0146 \theta\left(\frac{2 \sigma}{\mathrm{g}\left(\rho_{1}-\rho_{\mathrm{v}}\right)}\right)^{0.5}$

where $\theta$ corresponds to the static contact angle in degree.

Cooper [21] proposed a correlation for calculating nucleate boiling heat transfer coefficient taking into account the surface roughness and reduced pressure of the liquid,

$h_{\text {Cooper }}=55 p_{r}^{b}\left(-\log p_{r}\right)^{-0.55} M^{-0.5} q^{\prime \prime 0.67}$

where $b=0.12-0.2 \log R_{p}$, and $p_{r}, M$ and $R_{p}$ represent the reduced pressure, the molar mass of the working fluid, and the maximum peak height of surface roughness, respectively. In the present study, the correlation has been evaluated based on the average surface roughness, $R_{a}$, whereas Cooper's correlation includes the parameter, $R_{p}$. There has been some debate in the literature regarding the relation between these roughness parameters and boiling [24]. However, for the present analysis, the following expression suggested by Gorenflo [25] has been used:

$\mathrm{R}_{\mathrm{a}}=0.4 \mathrm{R}_{\mathrm{p}}$

Ribatski and Jabardo [22] proposed an empirical correlation for estimation of nucleate boiling heat transfer in terms of reduced pressures. The authors based on the experimental data for saturated pool boiling of halocarbon refrigerants on cylindrical surfaces of different materials:

$h_{R J}=q^{m} f_{W} p_{r}^{0.45}\left(-\log p_{r}\right)^{-0.8} R_{a}^{0.2} M^{-0.5}$

where

$m=0.9-0.3 p_{r}^{0.2}$

and $f_{W}$ is the surface material parameter.

Li et al. [23] analysed a semi-analytical heat transfer model with both static contact angle and surface roughness effects on pool boiling and, they indicated that the heat transfer could be expressed as a function of wall superheat, solid-liquid contact angle, surface roughness, influence parameter of the heating surface material and the fluid thermophysical properties. Using the experimental data of seven different fluids (water, ethanol, CCl4, acetone, n-hexane, R113, R141b), the authors proposed an improved correlation which is similar to Rohsenow's correlation as follows: 
$\frac{c_{p l} \Delta T_{s a t}}{h_{l v}}=0.013 C_{s}^{-0.33}\left[\frac{q^{\prime \prime}}{h_{l v} \mu_{l}} \sqrt{\frac{\sigma}{g\left(\rho_{l}-\rho_{v}\right)}}\right]^{0.33} \operatorname{Pr}_{l}$

where

$$
\begin{aligned}
C_{s} & =(1-\cos \theta)^{0.5}\left[1+\frac{5.45}{\left(R_{a}-3.5\right)^{2}+2.61}\right] \gamma^{-0.04} \theta \\
& =\operatorname{MAX}\left(\theta, 15^{\circ}\right)
\end{aligned}
$$

\section{Description of the experimental database}

Cardoso and Passos [1], Cardoso et al. [8] and Kiyomura et al. [17] obtained their nucleate boiling HTC results considering different heating surfaces and confinement conditions for n-Pentane, FC72 and FC87 and, DI-water, respectively.

Different test sections were used by the authors to obtain the experimental data. Cardoso and Passos [1] used two different test sections to analyze the roughness and the diameter of the heating surface (copper block of $12 \mathrm{~mm}$ and another of $20 \mathrm{~mm}$ diameter, both of them with $60 \mathrm{~mm}$ height cylinder). Four K-type thermocouples, fixed in the cylindrical part of the copper block, were used to determine the wall temperatures and the heat flux. The test section is heated by a cartridge heater of $177 \Omega$, embedded in the sample (Fig. 1). The working fluid used was n-Pentane, at saturation temperature and pressure of $1 \mathrm{bar}$, and different gap sizes were studied $(0.1 \mathrm{~mm} \leq s \leq 13 \mathrm{~mm})$. The uncertainty of the temperature measurement and the gap size were $\pm 0.2^{\circ} \mathrm{C}$ and $\pm 0.05 \mathrm{~mm}$, respectively. The experimental uncertainty for the heat flux and the heat transfer coefficient, for nucleate boiling regime, varied from $2.5 \%$ to $15 \%$ and $2 \%$ to $18 \%$, respectively.
In the work of Cardoso et al. [8], the test section consisted of a copper disc with a $12 \mathrm{~mm}$ diameter and $1 \mathrm{~mm}$ thickness, with three $\mathrm{K}$ thermocouples set in the disc. The copper disc is heated by an electrical resistance skin heater fixed by epoxy resin and is fixed to a piece of PVC. In fact, Cardoso et al. [8] analysed the nucleate boiling regime, for low and moderated heat flux $\left(\leq 40 \mathrm{~kW} / \mathrm{m}^{2}\right)$, for FC72 and FC87, at saturation temperature and atmospheric pressure. Different gap sizes $(s=0.1,0.2,0.3,0.4,0.5,1$ and $13 \mathrm{~mm}$ ) were examined on both a downward and an upward heating surface (Fig. 2). The uncertainty levels associated with the temperature and gap size were $\pm 0.6{ }^{\circ} \mathrm{C}$ and $\pm 0.05 \mathrm{~mm}$, respectively. The uncertainty for the HTC varies from $2 \%$ to $12 \%$.

Kiyomura et al. [17] performed an experimental investigation on the effects of surface roughness and nanoparticle deposition on the contact angle, surface wettability and pool boiling HTC under unconfined conditions. The experiments were carried out using copper surfaces with different roughnesses, and deionized water as the working fluid at a pressure of $98 \mathrm{kPa}$ and under saturated conditions. The test section consisted of a copper block ( $20 \mathrm{~mm}$ diameter and $60 \mathrm{~mm}$ height) containing three $\mathrm{K}$ thermocouples fixed in the copper cylinder (Fig. 3). These thermocouples are used to estimate the wall temperature and the heat flux. The temperature uncertainty was $\pm 0.4^{\circ} \mathrm{C}$. For all surfaces tested, the experimental uncertainty for the heat flux and for the HTC varied from $15.3 \%$ to $1.6 \%$, and from $15.9 \%$ to $2.6 \%$, respectively.

In this study, 2209 experimental data points concerning pool boiling on horizontal surfaces were analysed, in the range of fully established nucleate boiling under confined $(0.1 \mathrm{~mm} \leq \mathrm{s} \leq$ $0.7 \mathrm{~mm}$ ) and unconfined conditions. The thermophysical properties were obtained by the software EES (Equation Engineering Solver 7.345D 64-bit version). The data were analysed by using the

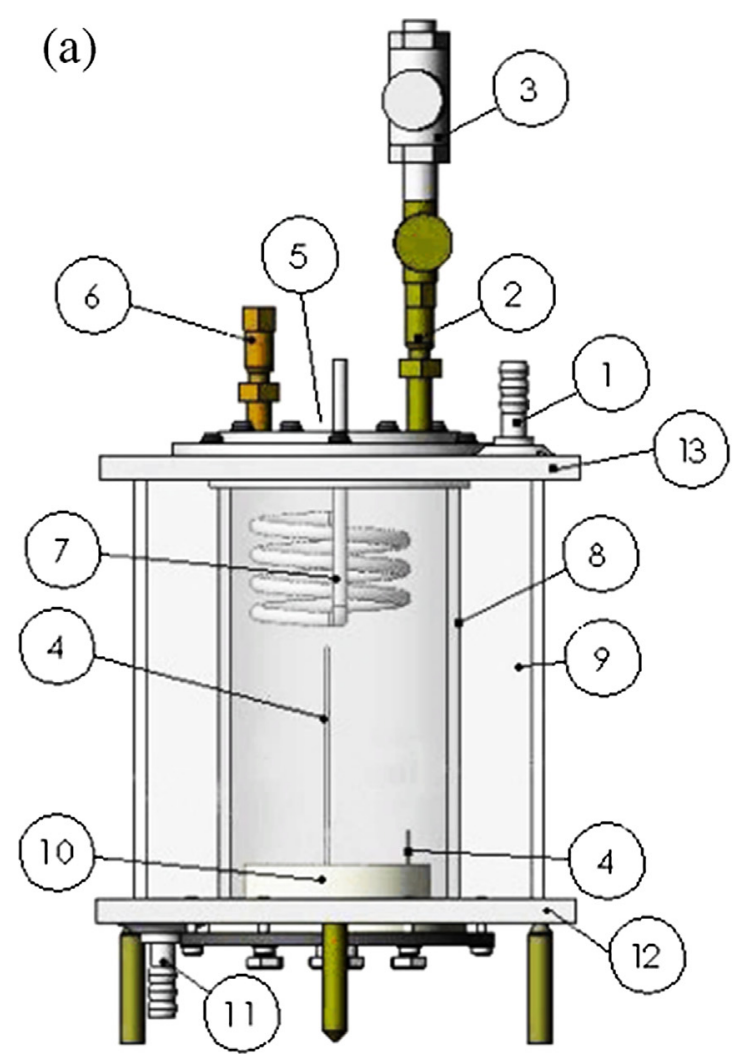

(b)
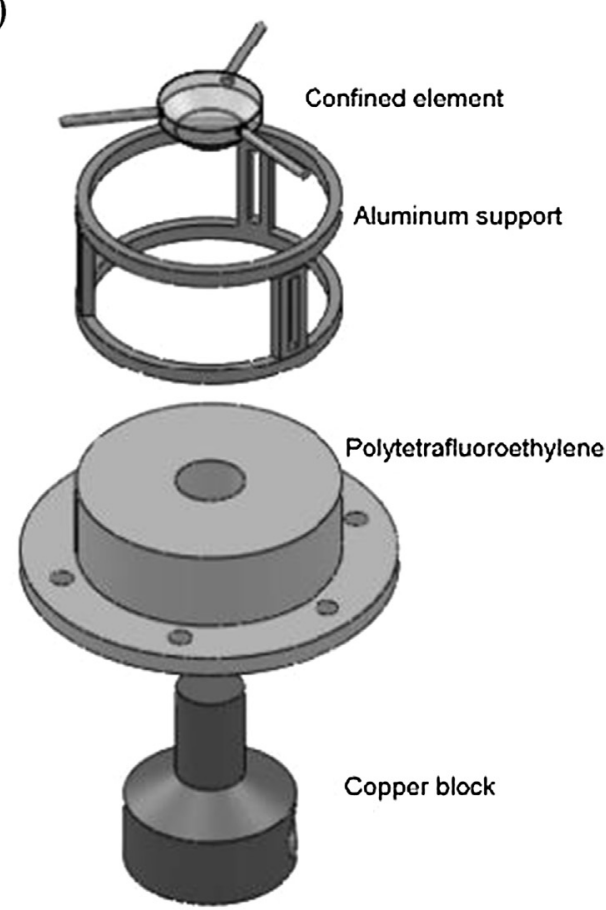

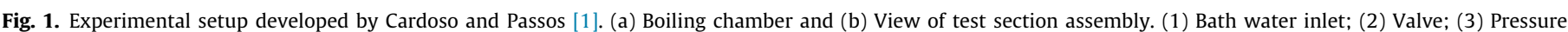

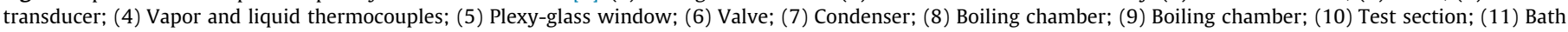
water outlet; (12) and (13) Stainless steel plates. 
least squares method implemented in Matlab $^{\circledR}$ version 8.1.0.604 (R2013a).

\subsection{Prediction of the database by using the known correlations}

In order to evaluate the capability of the correlations available in the literature to predict HTC results for pool boiling under confined and unconfined conditions, the experimental database $[1,8,17]$ were compared with the values of HTC calculated from the correlations of Gupta and Varshney as referred by Hameed et al. [18], Rohsenow [19], Stephan and Abdelsalam [20], Cooper [21], Ribatski and Jabardo [22] and, Li et al. [23]. Table 1 presents the results of the statistical analysis of the comparisons between experimental and predicted data for pool boiling under confined

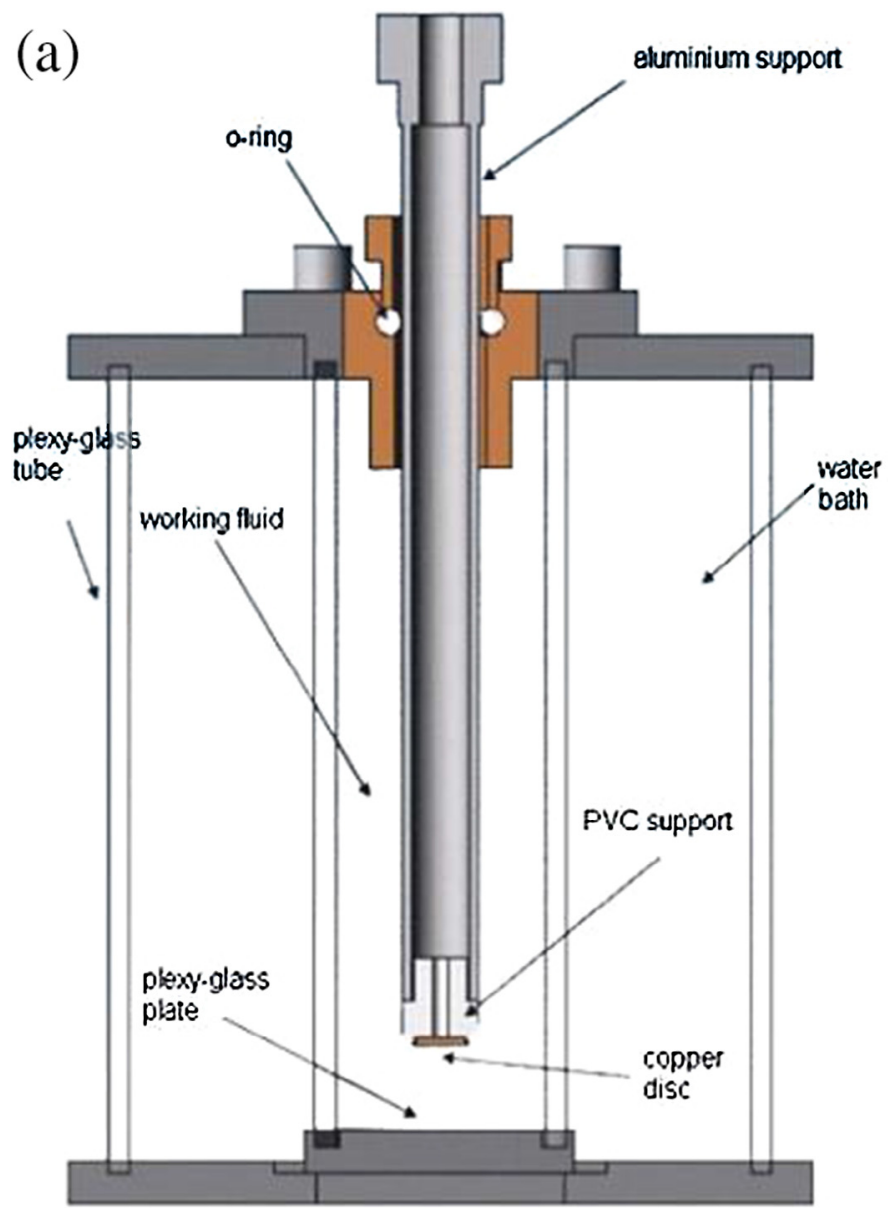

(b)

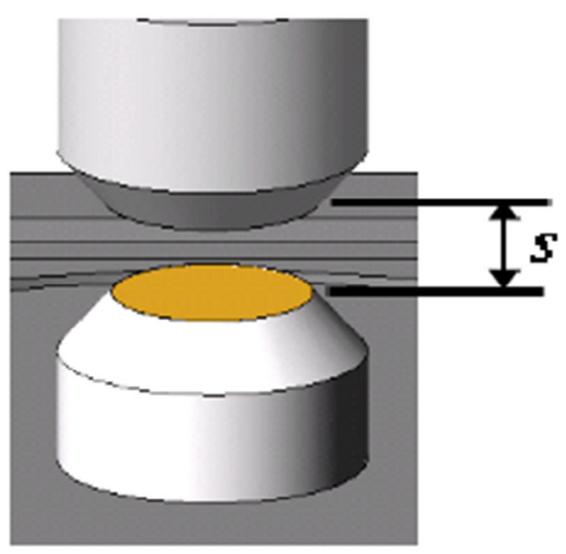

Fig. 2. Scheme of the experimental setup developed by Cardoso et al. [8]. (a) downward heating surface and (b) upward heating surface.

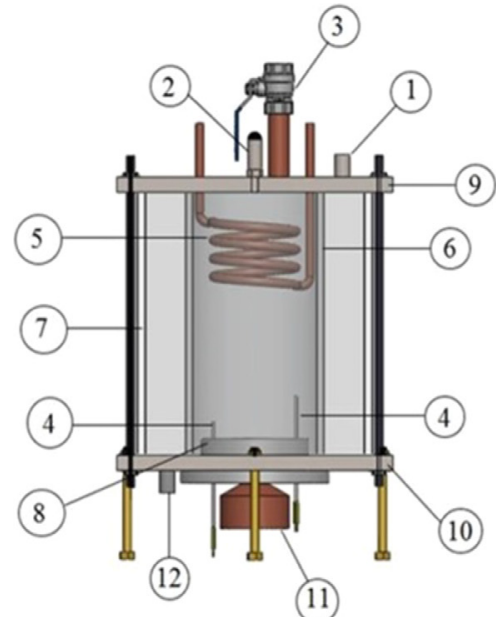

1. Water outlet

2. Pressure transducer

3. Valve

4. Thermocouples

5. Copper coil

6. Glass tube

7. Glass cube

8. Teflon

9. Upper stainless steel plate

10. Lower stainless steel plate

11. Copperblock

12. Water inlet

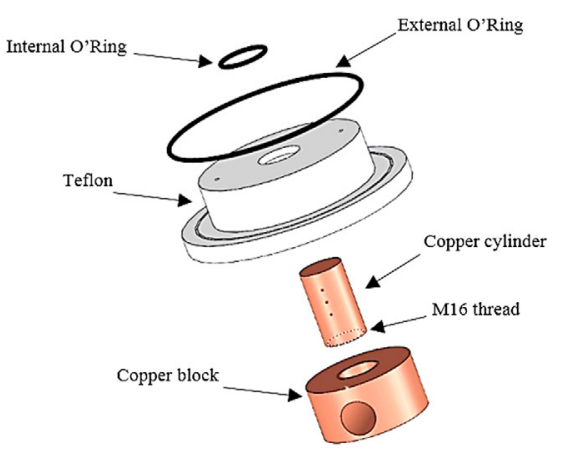

Fig. 3. View of test section assembly developed by Kiyomura et al. [17]. 
Table 1

Comparison between HTC experimental database used in the present study and HTC predictive methods from the literature.

\begin{tabular}{lll}
\hline Methods & $\varepsilon[\%]$ & $\gamma_{30}[\%]$ \\
\hline Gupta and Varshney [18] & 39 & 30 \\
Rohsenow [19] & 44 & 25 \\
Stephan and Abdelsalam [20] & 315 & 8 \\
Cooper [21] & 61 & 22 \\
Ribatski and Jabardo [22] & 27 & 58 \\
Li et al. [23] & 27 & 56 \\
\hline
\end{tabular}

and unconfined conditions, depicting the parcel of data predicted within an error band of $\pm 30 \%, \gamma_{30}$, and the relative average error, $\varepsilon$, defined as follows:

$\varepsilon=\frac{\sum_{i=1}^{N} \frac{\left|h_{c a l}-h_{\exp }\right|}{h_{\exp }}}{N}$

Despite of many parameters involved in the development of existing correlations for the pool boiling HTC prediction such as, the working fluid properties, the pressure, and the heating surface geometry and roughness, Table 1 indicates that the HTC experimental database did not accurately match any of the considered correlations. Ribatski and Jabardo [22] correlation provided the best result, predicting correctly $58 \%$ of the experimental database within an error band of $\pm 30 \%$. These correlations usually do not take into account the effect of the surface/liquid combination and the surface microstructure.

It was expected that the correlation proposed by Li et al. [23] showed the best performance, since their correlation takes into account both static contact angle and surface roughness effects on the pool boiling. However, this correlation under predicts most of the experimental database, predicting $56 \%$ of the data within the $\pm 30 \%$ error band. It is worth mentioning that this correlation is an improved version of Rohsenow's correlation, and as it can be seen in Table 1, Rohsenow [19] predicted only $25 \%$ of the database within an error band of $\pm 30 \%$.

The capability of the Stephan and Abdelsalam [20], and Cooper [21] correlations in predicting the experimental showed the worst performance. The comparison results from Table 1 revealed that an extrapolation of these correlations is only applicable over a narrow range. This fact can be related to the complexity of the coupled mechanisms involved in the accurate prediction of boiling heat transfer. Additionally, the existing correlations for the prediction of boiling processes is almost completely based on experimental investigations mainly for nucleate boiling regime under unconfined conditions.

The reports from the studies of Cardoso and Passos [1] and Cardoso et al. [8] indicated that pool boiling performance is greatly influenced by the heating surface conditions, and the gap size. Kiyomura et al. [17] also pointed out that the morphology of the heating surface interferes directly on the vapor bubble dynamics and the heat transfer mechanisms. Considering the various parameters involved in the boiling phenomena, a general correlation for pool boiling HTC is advisable based on the nondimensional analysis of the phenomena relating to the effect of the surface-liquid combination and the heating surface characteristics.

\section{New pool boiling HTC predictive method}

\subsection{Correlation development}

As previously mentioned, the HTC increases with increasing the confinement due to the fast growth of the bubble forming a microlayer with a large surface, which enhances its evaporation. For the unconfined case, the HTC enhancement is related to the increase in the liquid agitation. Thus, the proposed correlation takes into account the effect of different working fluids, gap sizes and contact angles. The newly developed correlation is obtained based on the Buckingham $(\pi)$ theorem to formulate the independent variables chosen to represent the dependent parameters. The application of this theorem first requires a decision on which of the parameters play a role on the nucleate boiling. The boiling phenomenon is dependent on the heat flux, $q^{\prime \prime}$; the saturation temperature, $T_{\text {sat }}$; the gravity acceleration, $g$; the latent heat of vaporization, $h_{l v}$; the surface tension, $\sigma$; the characteristic length (capillary length), $L_{b}$; the gap size, $s$; and the thermophysical properties of the fluid: density of the liquid and vapor phases, $\rho_{l}$ and $\rho_{\nu}$, respectively; specific heat of the liquid, $c_{p l}$; thermal conductivity, $k_{l}$; and viscosity of the liquid, $\mu_{l}$. Thus, the following functional relation can be written:

$h=f\left(q^{\prime \prime}, T_{s a t}, g, h_{l v}, \sigma, L_{b}, s, \rho_{l}, \rho_{v}, c_{p l}, k_{l}, \mu_{l}\right)$

The functional relationship involves 12 dimensions and, according to the Buckingham $(\pi)$ theorem, there are eight dimensionless parameters or settings in dimensionless groups. Algebraic manipulation of the $\pi$ values provides the main dimensionless groups, as follows:

$N u=N u\left(J a^{*}, \operatorname{Pr}_{l}, \operatorname{Re}_{b}, B o\right)$

where the Nusselt number is expressed as a function of the modified Jakob, Prandtl, Reynolds based on vapor bubble, and Bond numbers, respectively.

It is widely known that pool boiling heat transfer is related to the thermophysical properties of the working fluid and also, to the thermal and dynamic interaction between the heating surface and the vapor bubble. Thus, the modified Jakob number takes into account the sensible heat and the latent heat of vaporization, as follows,

$J a^{*}=\frac{c_{p l} T_{s a t}}{h_{l v}}$

According to Rohsenow [19], the heat transfer enhancement under boiling conditions is a consequence of the local fluid agitation in the region close to the heating surface promoted by the successive bubbles detachments. The Reynolds number, $R_{b}$, introduced by Rohsenow [19] for unconfined nucleate boiling, is based on the vapor bubble size at the departure from the heating surface, given by:

$\operatorname{Re}_{b}=\frac{\rho_{\nu} U_{b} L_{b}}{\mu_{l}}$

where $L_{b}=\left(\frac{\sigma}{g\left(\rho_{l}-\rho_{v}\right)}\right)^{1 / 2}$ is the characteristic length and, $U_{b}$ is the vapor bubble superficial velocity, defined as,

$U_{b}=\frac{q^{\prime \prime}}{\rho_{v} h_{l v}}$

In this study, the Reynolds number in Eq. (15) is modified taking into account the remarkable effect of the surface tension on the growth and departure of the vapor bubbles under confinement conditions, which strongly influence the boiling heat transfer performance as observed by Cardoso and Passos [1] and Cardoso et al. [8]. Thus, the modified Reynolds number is obtained by considering the effect of the contact angle of the vapor bubble departure in the nucleate boiling regime. As pointed out by Cheng and Mewes [26], static contact angle, $\theta$, is one of the most important parameters in boiling phenomena that characterize the wettability of the heating surface. Therefore, the modified Reynolds number is given by: 
$\operatorname{Re}_{b}^{*}=\frac{D_{b} q^{\prime \prime}}{\mu_{l} h_{l v}}$

where the bubble departure diameter, $D_{b}$, is estimated considering the effect of the contact angle on bubble departure in nucleate boiling regime calculated as follows:

$D_{b}=0.0208 \theta L_{b}$

where, the contact angle is considered in the range of $\theta<10^{\circ}$ and $75^{\circ}<\theta<95^{\circ}$ for wetting surface and non-wetting surface fluids, respectively. The Fritz's [27] model is one of the well-founded models to predict the bubble diameter.

The Prandtl number of the liquid was used by Rohsenow [19] to develop his correlation. According to Rohsenow [19], the Prandtl number is important because the heat transfer occurs directly from the heating surface to the adjacent liquid, adapting a single-phase forced convection heat transfer model to nucleate pool boiling. Since the Prandtl number of the liquid is an important parameter

Table 2

Range of the dimensionless groups.

\begin{tabular}{lll}
\hline Dimensionless number & Confined case & Unconfined case \\
\hline$N u$ & $2.26 \leq N u \leq 167.60$ & $2.52 \leq N u \leq 257.71$ \\
$\mathrm{Re}_{b}{ }^{*}$ & $0.00015 \leq \mathrm{Re}_{b}{ }^{*} \leq 0.22$ & $0.00016 \leq \mathrm{Re}_{b}{ }^{*} \leq 8.23$ \\
$\mathrm{Pr}_{l}$ & $3.62 \leq \mathrm{Pr}_{l} \leq 13.30$ & $1.80 \leq \mathrm{Pr}_{l} \leq 13.30$ \\
$\mathrm{Ja}^{*}$ & $2.04 \leq \mathrm{J} a^{*} \leq 3.84$ & $0.7 \leq \mathrm{Ja}{ }^{*} \leq 3.84$ \\
$\mathrm{Bo}$ & $0.06 \leq \mathrm{Bo} \leq 1.37$ & $5.18 \leq \mathrm{Bo} \leq 17.79$ \\
\hline
\end{tabular}

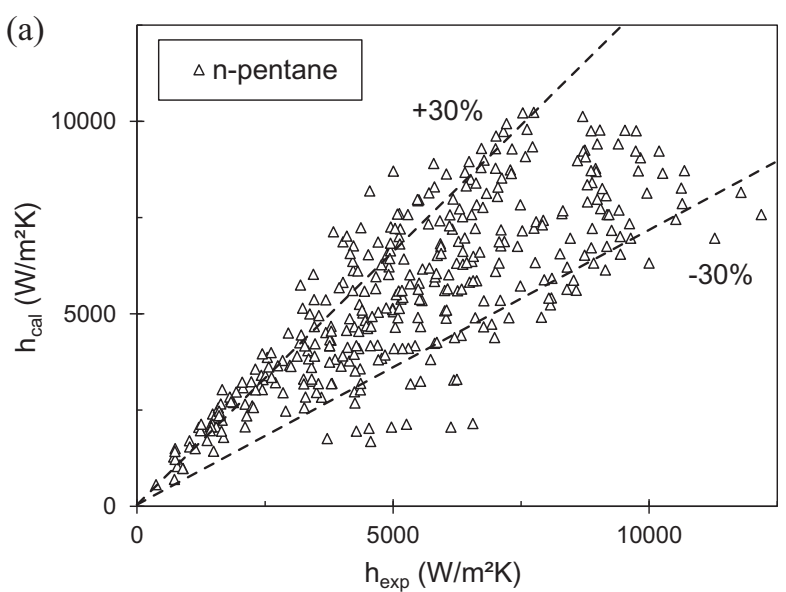

which affects the boiling heat transfer, it is considered as a correlating parameter in the form:

$\operatorname{Pr}_{l}=\frac{c_{p l} \mu_{l}}{k_{l}}$

Due to the influence of the gap size on the HTC, the Bond number, $B$, defined as the ratio between the gap size (s), i.e., gap between the heating surface and the confining element, and the capillary length is also considered as one of the $\pi$ groups in the proposed correlation, as follows:

$B o=\frac{s}{\left[\frac{\sigma}{g\left(\rho_{l}-\rho_{v}\right)}\right]^{1 / 2}}$

Once all the $\pi$ groups/parameters were identified, the new correlation for the pool boiling HTC under confined and unconfined conditions can be written as,

$\frac{h L_{b}}{k_{l}}=C\left[\left(\frac{c_{p l} T_{s a t}}{h_{l v}}\right)^{a 1}\left(\frac{c_{p l} \mu_{l}}{k_{l}}\right)^{a 2}\left(\frac{D_{b} q^{\prime \prime}}{\mu_{l} h_{l v}}\right)^{a 3}\left(\frac{s}{L_{b}}\right)^{a 4}\right]$

Based on the regression analysis of the experimental database, in the range of fully established nucleate boiling under confined $(0.1 \mathrm{~mm} \leq s \leq 1 \mathrm{~mm})$ and unconfined $(s=13 \mathrm{~mm})$ conditions by using the least squares method implemented in Matlab ${ }^{\circledR}$, the following correlation is proposed:

$\frac{h L_{b}}{k_{l}}=154\left[\left(\frac{c_{p l} T_{s a t}}{h_{l v}}\right)^{1.72}\left(\frac{c_{p l} \mu_{l}}{k_{l}}\right)^{-0.34}\left(\frac{D_{b} q^{\prime \prime}}{\mu_{l} h_{l v}}\right)^{0.62}\left(\frac{s}{L_{b}}\right)^{-0.05}\right]$
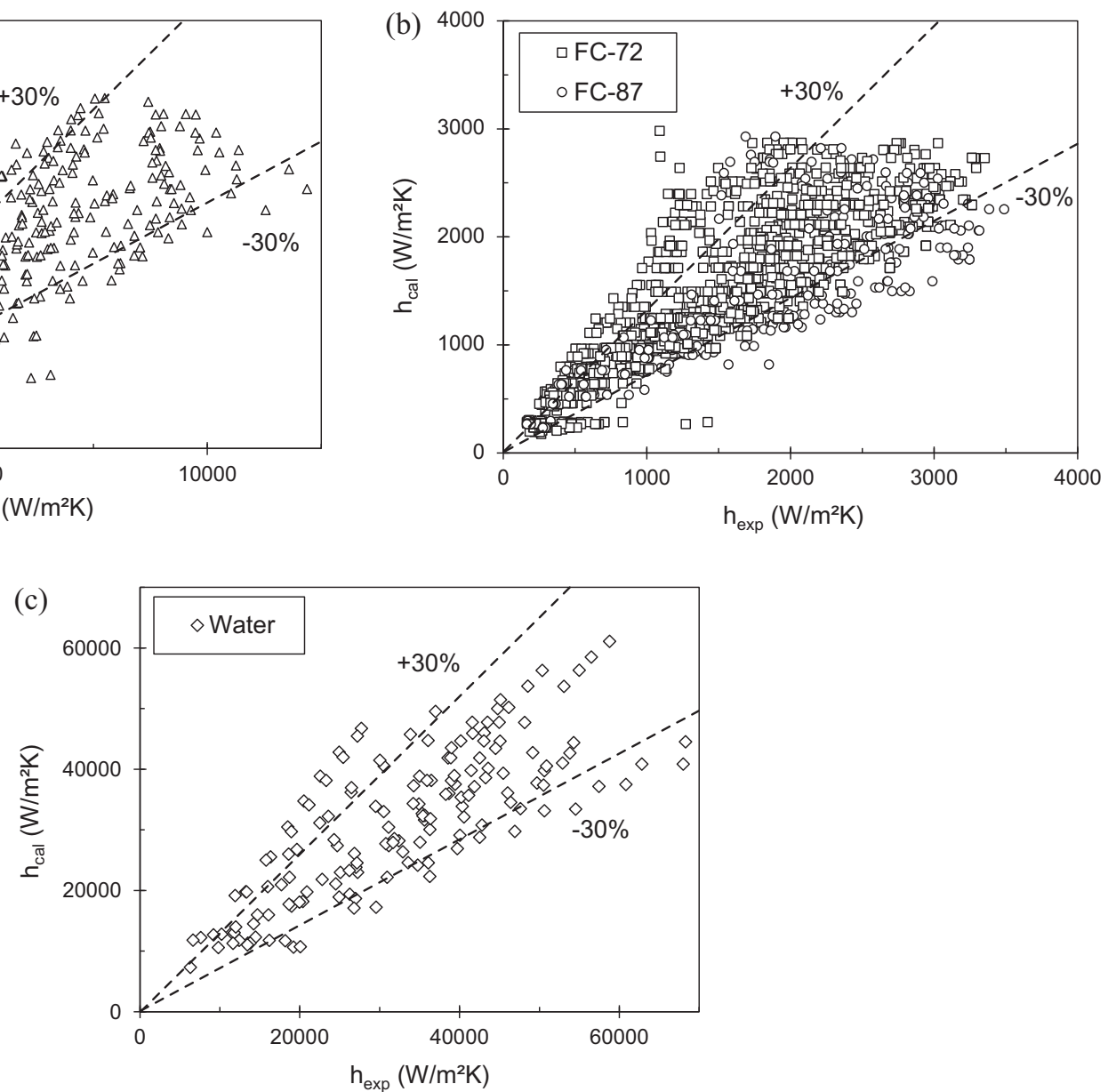

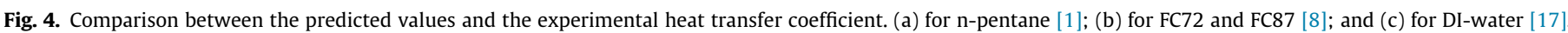


Table 2 shows the range of each dimensionless group of the experimental database, for the confined and unconfined case.

\subsection{Evaluation of the proposed correlation}

In order to evaluate the performance of the proposed correlation, the predicted values and the experimental HTCs are plotted in the Fig. 4. The proposed correlation predicts mostly of the experimental database, predicting $70 \%$ of the data within the $\pm 30 \%$ error band and with relative average error (Eq. (11)) of $24 \%$.

This is quite reasonable since the effect of different working fluids (thermophysical properties and heating surface/liquid combination), gap size and surface roughness are well captured by the correlation. Thus, from this result one can infer that the nondimensional analysis performed in this work is a suitable way to determine a general correlation to predict the pool boiling heat transfer.
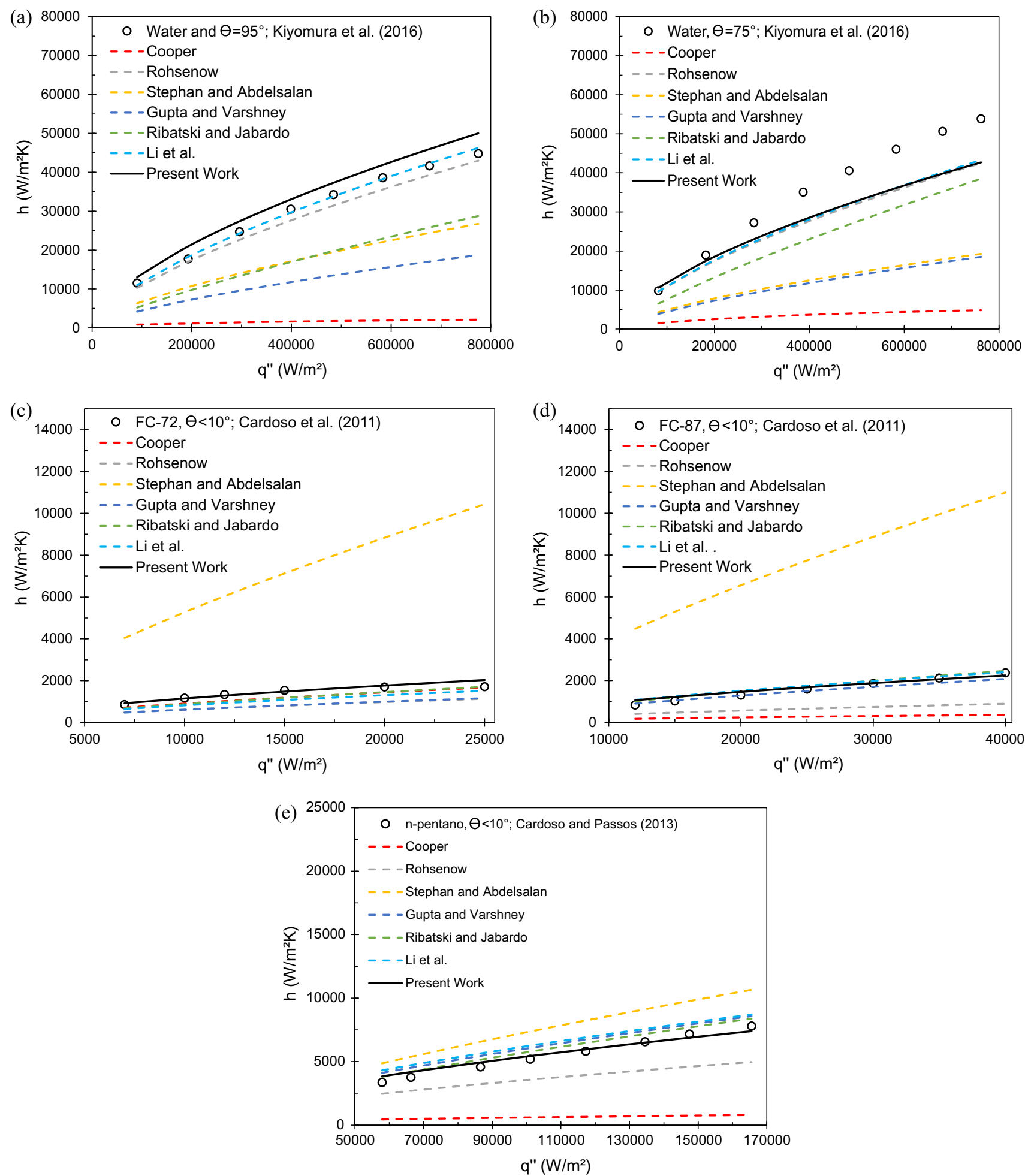

Fig. 5. Comparison between the experimental database and the estimated HTC by the literature and also, by the correlation proposed in the present study. 


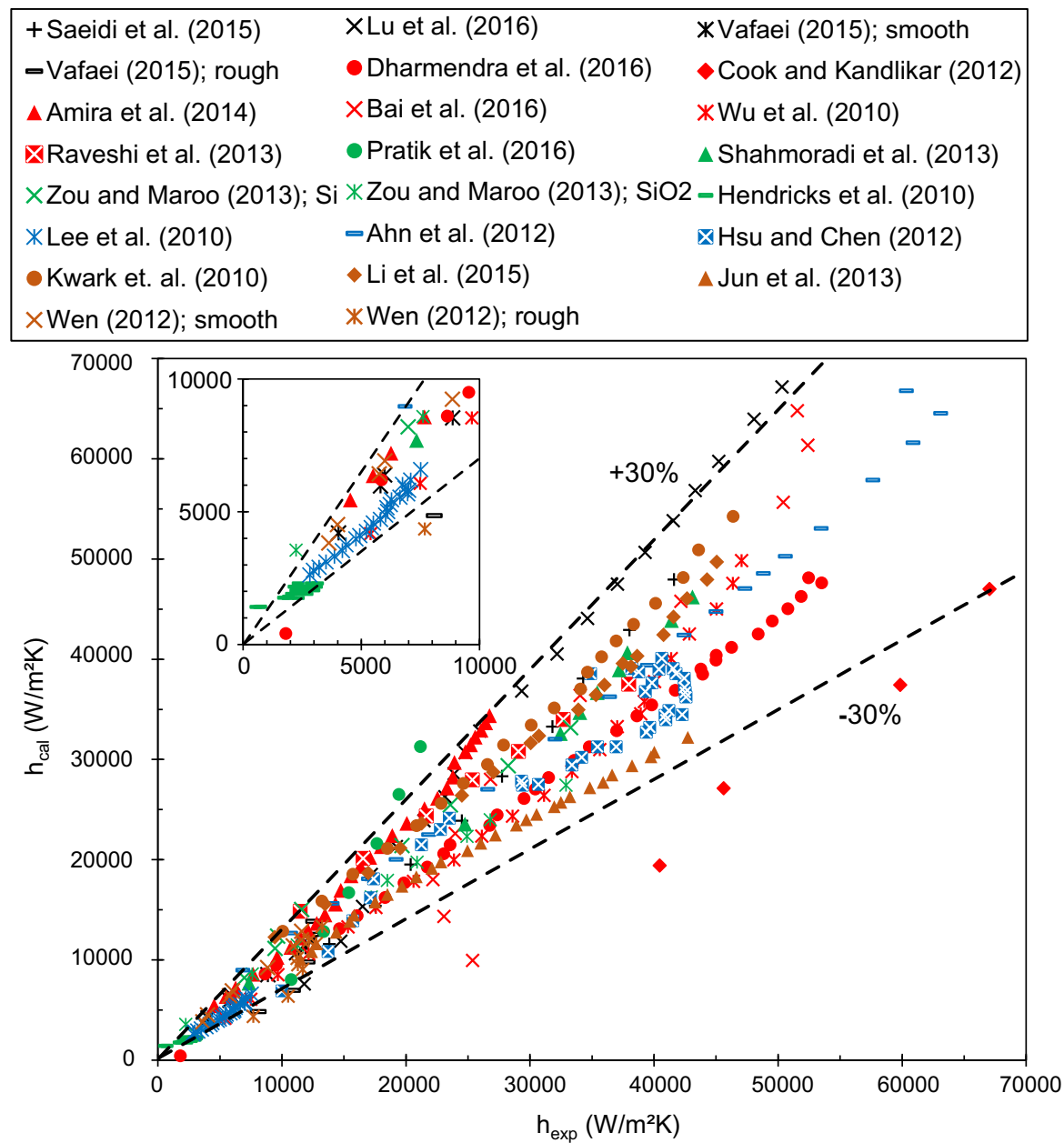

Fig. 6. Predicted versus experimental boiling HTC for independent data of DI-water from literature.

A predictive correlation must not only present reasonable statistical similarity with experimental results, but it must also capture the trends of the experimental data. In this context, Fig. 5 depicts a comparison among the experimental database $[1,8,17]$, the corresponding predicted values by known correlations from the literature and also, by the proposed correlation. According to Fig. 5, the proposed correlation correctly predicts the experimental trends for different pool boiling conditions, including different ranges of static contact angles as shown in Fig. 5a-e.

For high static contact angles (DI-water, Fig. 5a and b), the predictive methods of Rohsenow [19] and Li et al. [23] provide results that are close and capture the main trend of the experimental database; however, Gupta and Varshney as referred by [18], Stephan and Abdelsalam [20], Cooper [24] and, Ribatski and Jabardo [22] fail to predict the experimental trend reported by Cardoso and Passos [1], Cardoso et al. [8] and, Kiyomura et al. [17]. Considering the use of refrigerant as the working fluid and as displayed in Fig. $5 \mathrm{c}-$ e, the predictive methods of Gupta and Varshney [18], Ribatski and Jabardo [22], and Li et al. [23] also provide results that are close to the experimental database for FC72, FC87 and n-pentane.

Moreover, the performance of the proposed correlation was evaluated through comparisons with 589 experimental data points obtained by others authors. It was obtained experimental data points from Li et al. [4], Saeidi et al. [28], Lu et al. [29], Vafaei [30], Dharmendra et al. [31], Cooke and Kandlikar [32], Bai et al. [33], Wu et al. [34], Raveshi et al. [35], Shahmoradi et al. [36], Ahn et al. [37], Hsu and Chen [38], Kwark et al. [39], Jun et al. [40], Wen [41], Zou and Maroo [42], Amiri et al. [43], Pratik et al.
[44], Hendricks et al. [45], and Lee et al. [46] for DI-water boiling on different heating surface materials (copper, stainless steel, silver, $\mathrm{Si}$ and $\mathrm{SiO}_{2}$, aluminium and nickel). The data from the respective authors were compared with the corresponding values estimated through the proposed correlation as shown in Fig. 6. Also, data for pool boiling of refrigerants, HFE7100, FC72, FC87, R12 and R134a, were obtained from the studies of Souza et al. [15], Wu et al. [34], Sarangi et al. [47], Misale et al. [48], Jaikumar and Kandlikar [49], Moehrle and Chung [50], and Ray et al. [51]. The data from the respective authors were also compared with the corresponding values estimated through the proposed correlation as shown Fig. 7.

According to Figs. 6 and 7 the proposed correlation correctly predicts the independent experimental data from the literature, predicting $91.8 \%$ of the data within the $\pm 30 \%$ error band, even though: (i) their experimental results are obtained for different heating surfaces from that used by the experimental database $[1,8,17]$; (ii) their data include different refrigerants from those used in the development of the present correlation. Additionally, the effect of gap size on boiling heat transfer performance observed on experimental data obtained by Misale et al. [48] were well captured by the proposed correlation despite of the fact that Misale et al. [48] data were obtained using different confinement conditions from those ranges considered in the present study.

In general, the proposed correlation accurately predicts the experimental data obtained elsewhere for different working fluids, heating surface materials and ranges of operating conditions considered in their studies. 


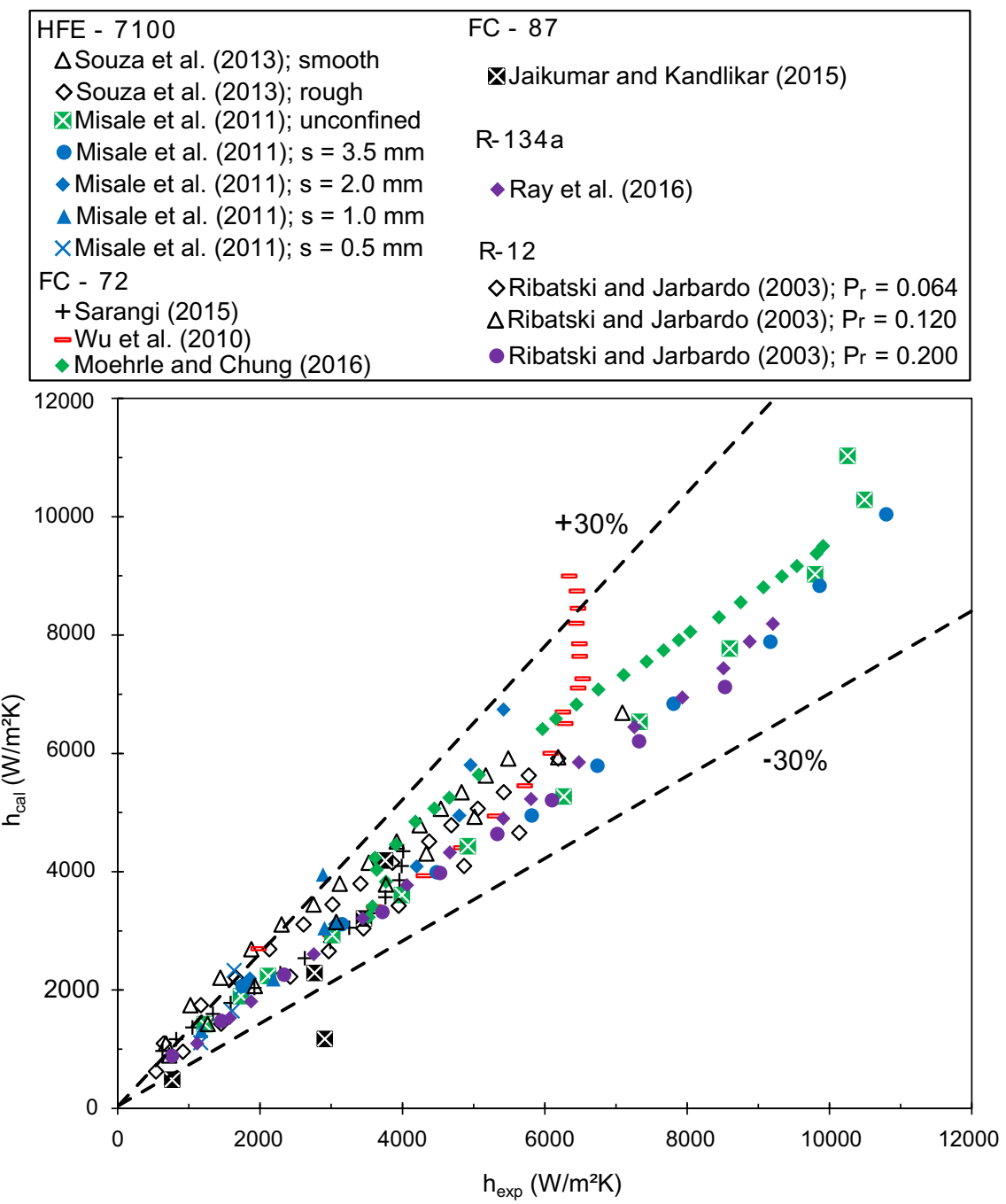

Fig. 7. Predicted versus experimental boiling HTC for independent data of refrigerants from literature.

\section{Conclusions}

The following conclusions can be drawn from the present study:

- A dimensionless analysis of the most important parameters was carried out and a general correlation to predict the pool boiling heat transfer under confined and unconfined conditions has been developed, based on experimental data obtained by Cardoso and Passos [1], Cardoso et al. [8], and Kiyomura et al. [17].

- Among the predictive methods available in the literature, the heat transfer correlation of Ribatski and Jabardo [22] provided the best result but it predicted only $58 \%$ of the database within an error band of $\pm 30 \%$ with relative average error of $27 \%$.

- The proposed correlation accurately predicts the experimental results obtained by Cardoso and Passos [1], Cardoso et al. [8], and Kiyomura et al. [17], predicting 70\% of the data within an error band of $\pm 30 \%$ and absolute mean deviation of $24 \%$. The present correlation captures the trend of experimental data in the nucleate boiling regime independently of the confinement conditions, surface roughness and working fluids.

- The correlation developed in the present study also predicts $91.8 \%$ (within the $\pm 30 \%$ error band) of data obtained from literature for different working fluids, heating surface materials and, also, different range of operating conditions considered in those studies.

\section{Acknowledgments}

The authors are grateful for the financial support from the PPGEM - UNESP/FEIS, from the National Counsel of Technological and Scientific Development of Brazil (CNPq grant number 458702/2014-5), from São Paulo Research Foundation - FAPESP (grant numbers 2013/15431-7 and 2014/19497-5) and from a CAPES sponsored postdoctoral fellowship for Mogaji T. S. The authors also extend their gratitude to Prof. Julio César Passos from Federal University of Santa Catarina for his important contribution to this work.

\section{Appendix A. Supplementary material}

Supplementary data associated with this article can be found, in the online version, at http://dx.doi.org/10.1016/j.applthermaleng. 2017.08.135.

\section{References}

[1] E.M. Cardoso, J.C. Passos, Nucleate boiling of n-pentane in a horizontal confined space, Heat Transfer Eng. 34 (5-6) (2013) 470-478.

[2] Y.-Y. Li, Z.-H. Liu, B.-C. Zheng, Experimental study on the saturated pool boiling heat transfer on nano-scale modification surface, Int. J. Heat Mass Transfer 84 (2015) 550-561. 
[3] J. Bonjour, M. Lallemand, Effects of confinement and pressure on critical heat flux during natural convective boiling in vertical channels, Int. Commun. Heat Mass Transfer 24 (2) (1997) 191-200.

[4] M. Kole, T.K. Dey, Investigations on the pool boiling heat transfer and critical heat flux of ZnO-ethylene glycol nanofluids, Appl. Therm. Eng. 37 (2012) 112119.

[5] E. Ishibashi, K. Nishikawa, Saturated boiling heat transfer in narrow spaces, Int. J. Heat Mass Transfer 12 (1969) 861-894.

[6] Y. Katto, S. Yokoya, K. Teraoka, Nucleate and transition boiling in a narrow space between two horizontal, parallel disk-surface, Bull. JSME 20 (1977) 638643.

[7] B. Stutz, M. Lallemand, F. Raimbault, J.C. Passos, Nucleate and transition boiling in narrow horizontal spaces, Heat Mass Transfer 45 (7) (2009) 929-935.

[8] E.M. Cardoso, O. Kannengieser, B. Stutz, J.C. Passos, FC72 and FC87 nucleate boiling inside a narrow horizontal space, Exp. Therm. Fluid Sci. 35 (2011) 1038-1045.

[9] L. Yin, L. Jia, P. Guan, D. Liu, Experimental investigation on bubble confinement and elongation in microchannel flow boiling, Exp. Therm. Fluid Sci. 54 (2014) 290-296.

[10] Y.H. Zhao, T. Tsuruta, C.Y. Ji, Experimental study of nucleate boiling heat transfer enhancement in confined space, Exp. Therm. Fluid Sci. 28 (2003) 9-16.

[11] G. Guglielmini, M. Misale, A. Priarone, Combined orientation and confinement effects on saturated pool boling of a dieletric liquid, in: 13th International Heat Transfer Conference, 2006, Sydney, Australia.

[12] G. Hetsroni, A. Mosyak, R. Rozenblit, E. Pogrebnyak, Z. Segal, Natural convection boiling of water and surfactant solutions having negligible environmental impact in vertical confined space, Int. J. Multiphase Flow 35 (2009) 20-33.

[13] J.M.S. Jabardo, E.F. Silva, G. Ribatski, S.F. Barros, Evaluation of the Rohsenow correlation through experimental pool boiling of halocarbon refrigerants on cylindrical surfaces, J. Braz. Soc. Mech. Sci. Eng. 26 (2004) 218-230.

[14] C.-Y. Yang, C.-F. Liu, Effect of coating layer thickness for boiling heat transfer on micro porous coated surface in confined and unconfined spaces, Exp. Therm. Fluid Sci. 47 (2013) 40-47.

[15] R.R. Souza, J.C. Passos, E.M. Cardoso, Influence of nanoparticle size and gap size on nucleate boiling using HFE7100, Exp. Therm. Fluid Sci. 59 (2013) 195-201.

[16] L.V. Heitich, J.C. Passos, E.M. Cardoso, M.F. Silva, A.N. Klein, Nucleate boiling of water using nanostructured surfaces, J. Braz. Soc. Mech. Sci. Eng. 36 (2014) $181-192$.

[17] I.S. Kiyomura, L.L. Manetti, A.P. da Cunha, G. Ribatski, E.M. Cardoso, An analysis of the effects of nanoparticles deposition on characteristics of the heating surface and on pool boiling of water, Int J. Heat Mass Transfer 106 (2017) 666674.

[18] M.S. Hameed, A.R. Khan, A.A. Mahdi, Modeling a general equation for pool boiling heat transfer, Adv. Chem. Eng. Sci. 3 (3) (2013) 294-303.

[19] W.M. Rohsenow, A method of correlating heat transfer data for surface boiling of liquids, Trans. ASME J. Heat Transfer 74 (1952) 969-976.

[20] K. Stephan, M. Abdelsalam, Heat transfer correlations for natural convection boiling, Int J. Heat Mass Transfer 23 (1980) 73-87.

[21] M.G. Cooper, Saturation nucleate pool boiling: a simple correlation, in: 1st UK National Conference on Heat Transfer, vol. 2, 1984, pp. 785-793.

[22] G. Ribatski, J.M.S. Jabardo, Experimental study of nucleate boiling of halocarbon refrigerants on cylindrical surfaces, Int. J. Heat Mass Transfer 46 (23) (2003) 4439-4451.

[23] Y.Y. Li, Y.J. Chen, Z.H. Liu, A uniform correlation for predicting pool boiling heat transfer on plane surface with surface characteristics effect, Int. J. Heat Mass Transfer 77 (2014) 809-817.

[24] J.M.S. Jabardo, G. Ribatski, E. Stelute, Roughness and surface material effects on nucleate boiling heat transfer from cylindrical surfaces to refrigerants R-134a and R-123, Exp. Therm. Fluid Sci. 33 (2009) 579-590.

[25] D. Gorenflo, VDI-Heat Atlas, sixth ed., VDI-Verlag, Dusseldorf, 1994.

[26] L. Cheng, D. Mewes, A. Luke, Boiling phenomena with surfactants and polymeric additives: a state-of-the-art review, Int. J. Heat Mass Transfer 50 (2007) 2744-2771.

[27] W. Fritz, Berechnung des Maximalvolumens von Dampfblasen ed., Phys. Z 36 (1935) 379-384.
[28] D. Saeidi, A.A. Alemrajabi, N. Saeidi, Experimental study of pool boiling characteristic of an aluminized copper surface, Int. J. Heat Mass Trans. 85 (2015) 239-246.

[29] L. Lu, T. Fu, Y. Tang, T. Tang, B. Tang, Z. Wan, A novel in-situ nanostructure forming route and its application in pool-boiling enhancement, Exp. Therm. Fluid Sci. 72 (2016) 140-148.

[30] S. Vafaei, Nanofluid pool boiling heat transfer phenomenon, Powder Technol 277 (2015) 181-192.

[31] M. Dharmendra, S. Suresh, C.S. Sujith Kumar, Q. Yang, Pool boiling heat transfer enhancement using vertically aligned carbon nanotube coatings on a copper substrate, Appl. Therm. Eng. 99 (2016) 61-71.

[32] D. Cooke, S.G. Kandlikar, Effect of open microchannel geometry on pool boiling enhancement, Int. J. Heat Mass Transfer 55 (2012) 1004-1013.

[33] L. Bai, L. Zhang, J. Guo, G. Lin, X. Bu, D. Wen, Evaporation/boiling heat transfer characteristics in an artery porous structure, Appl. Therm. Eng. 104 (2016) 587-595.

[34] W. Wu, H. Bostanci, L.C. Chow, Y. Hong, M. Su, J.P. Kizito, Nucleate boiling heat transfer enhancement for water and FC-72 on titanium oxide and silicon oxide surfaces, Int. J. Heat Mass Transfer 53 (2010) 1773-1777.

[35] M.R. Raveshi, A. Keshavarz, M.S. Mojarrad, S. Amiri, Experimental investigation of pool boiling heat transfer enhancement of alumina-water-ethylene glycol nanofluids, Exp. Therm. Fluid Sci. 44 (2013) 805-814.

[36] Z. Shahmoradi, N. Etesami, M. Nasr Esfahany, Pool boiling characteristics of nanofluid on flat plate based on heater surface analysis, Int. Commun. Heat Mass Transfer 47 (2013) 113-120.

[37] H.S. Ahn, S.H. Kang, M.H. Kim, Visualized effect of alumina nanoparticles surface deposition on water flow boiling heat transfer, Exp. Therm. Fluid Sci. 37 (2012) 154-163.

[38] C.-C. Hsu, P.-H. Chen, Surface wettability effects on critical heat flux of boiling heat transferusing nanoparticle coatings, Int. J. Heat Mass Transfer 55 (2012) 3713-3719.

[39] S.M. Kwark, M. Amaya, R. Kumar, G. Moreno, S.M. You, Effects of pressure orientation, and heater size on pool boiling of water with nanocoated heaters, Int. J. Heat Mass Transfer 53 (2010) 5199-5208.

[40] S. Jun, S.-R. Suman, A.L. Yarin, Pool boiling on nano-textured surfaces, Int. J Heat Mass Transfer 62 (2013) 99-111.

[41] D. Wen, Influence of nanoparticles on boiling heat transfer, Appl. Therm. Eng. 41 (2012) 2-9.

[42] A. Zou, S.C. Maroo, Critical height of micro/nano structures for pool boiling heat transfer enhancement, Appl. Phys. Lett. 103 (2013) 221602.

[43] A. Amiri, M. Shanbedi, H. Amiri, S.Z. Heris, S.N. Kazi, B.T. Chew, H. Eshghi, Pool boiling heat transfer of CNT/water nanofluids, Appl. Therm. Eng. 71 (2014) 450-459.

[44] K.C. Pratik, A. Nammari, S.T. Ashton, A.L. Moore, Saturated pool boiling heat transfer from vertically oriented silicon surfaces modified with foam-like hexagonal boron nitride nanomaterials, Int. J. Heat Mass Transfer 95 (2016) 964-971.

[45] T.J. Hendricks, S. Krishnan, C. Choi, C.-H. Chang, B. Paul, Enhancement of poolboiling heat transfer using nanostructured surfaces on aluminum and copper, Int. J. Heat Mass Transfer 53 (2010) 3357-3365.

[46] C.Y. Lee, M.M.H. Bhuiya, K.J. Kim, Pool boiling heat transfer with nano-porous surface, Int. J. Heat Mass Transfer 53 (2010) 4274-4279.

[47] S. Sarangi, J.A. Weibel, S.V. Garimella, Effect of particle size on surface-coating enhancement of pool boiling heat transfer, Int. J. Heat Mass Transfer 81 (2015) 103-113.

[48] M. Misale, G. Guglielmini, A. Priarone, Nucleate boiling and critical heat flux of HFE-7100 in horizontal narrow spaces, Exp. Therm. Fluid Sci. 35 (2011) 772 779.

[49] A. Jaikumar, S.G. Kandlikar, Enhanced pool boiling for electronics cooling using porous fin tops on open microchannels with FC-87, Appl. Therm. Eng. 91 (2015) 426-433.

[50] R.E. Moehrle, J.N. Chung, Pool boiling heat transfer driven by an acoustic standing wave in terrestrial gravity and microgravity, Int. J. Heat Mass Transfer 93 (2016) 322-336.

[51] M. Ray, S. Deb, S. Bhaumik, Pool boiling heat transfer of refrigerant R-134a on $\mathrm{TiO}_{2}$ nano wire arrays surface, Appl. Therm. Eng. 107 (2016) 1294-1303. 